\title{
BURNOUT AND JOB STRESS IN A LOCAL GOVERNMENT: THE MODERATING EFFECT OF SENSE OF COHERENCE
}

\author{
S. ROTHMANN \\ L.T.B. JACKSON \\ M.M. KRUGER \\ WorkWell: Research Unit for People, Policy and Performance, \\ Faculty of Economic \& Management Sciences \\ PU for CHE
}

\begin{abstract}
The objective of this research was to establish the relationship between burnout and job stress, and to determine whether sense of coherence moderates the effects of job stress on burnout of employees in a local government. A cross-sectional survey design was used. The sample consisted of 270 employees of a local government. The Maslach Burnout Inventory, Job Stress Indicator and Orientation to Life Questionnaire were administered. Canonical analysis showed that a weak sense of coherence combined with stress because of job demands and a lack of resources were associated with all three components of burnout. Structural equation modelling showed that sense of coherence moderated the effect of job stress on exhaustion. Cynicism mediated the effect of exhaustion on professional efficacy.
\end{abstract}

\section{OPSOMMING}

Die doelstelling van hierdie navorsing was om die verwantskap tussen psigiese uitbranding en werkstres te bepaal en om te bepaal of koherensiesin die effek van werkstres op uitbranding by werknemers binne ' $n$ plaaslike owerheid modereer. 'n Eenmalige dwarssnee opname-ontwerp is gebruik. Die steekproef het bestaan uit 270 werknemers van 'n plaaslike owerheid. Die Maslach Uitbrandingsvraelys, die Werkstres-Indikator en die Lewensoriëntasievraelys is afgeneem. Kanoniese analise het getoon dat 'n swak koherensiesin, asook stres a.g.v. hoë werkseise en 'n gebrek aan organisasie-ondersteuning geassosieer was met al drie komponente van uitbranding. Strukturele vergelykingsmodellering het aangetoon dat koherensiesin die effek van werkstres op uitbranding modereer. Sinisme het die effek van uitputting op professionele doeltreffendheid gemedieer.

An effective and efficient local government system is essential for economic development in South Africa. However, local governments face high demands for basic services in previously disadvantaged communities, while they have limited resources. Problems such as HIV/AIDS and poverty in the townships aggravate problems with service delivery. Because of transformation in local governments, promotions were put on hold and managers had to reapply for their jobs. A moratorium was placed on the appointment of new personnel, which has led to understaffing in most departments. The above-mentioned changes result in new demands on employees, which often have to be managed without having the necessary resources. These factors contribute to job stress, which could lead to burnout.

Schaufeli and Enzmann (1998, p. 36) define burnout as follows: "Burnout is a persistent, negative, work-related state of mind in 'normal' individuals that is primarily characterized by exhaustion, which is accompanied by distress, a sense of reduced effectiveness, decreased motivation, and the development of dysfunctional attitudes and behaviours at work." However, stress should not be confused with burnout. According to Schaufeli and Enzmann (1998), burnout can be considered as a particular kind of prolonged job stress. An individual experiences job stress when the demands of the workplace exceed his or her adaptive responses. Burnout is a particular, multidimensional, chronic stress reaction that goes beyond the experience of mere exhaustion. Burnout is seen as the final step in a progression of unsuccessful attempts to cope with a variety of negative stress conditions.

Stress, in the majority of stress theories and models, is described as a series of factors that have their beginnings in one's actual surroundings and conclude with the individual's reactions. The individual forms a conception of the objective situation through his or her subjective interpretation of the situation (Beehr, 2000). The stress process involves an interaction

Requests for copies should be addressed to: S Rothmann, WorkWell: Research Unit for People, Policy and Performance, Faculty of Economic \& Management Sciences, PU for CHE, Private Bag X6001, Potchefstroom, 2520 between the individual and environment where the discrepancy between an individual's perceived threats and the resources he or she sees as available for facing the threats leads to the experience of stress (Cooper, 2000). By means of weighing the demands/threats against the available resources, an individual makes an evaluation of the situation and forms an impression of its significance. This appraisal is then followed by immediate reactions. Both appraisals of and reactions to a given situation vary from individual to individual due to, for example individual characteristics.

There are factors that may either alleviate or aggravate the experiences and reactions of an individual towards a stressor. In the behavioural sciences, these factors are referred to as moderators, which means that they moderate or affect the relation between the stressor and its consequences. One characteristic which might have a positive effect on the relation between a stressor and outcome (e.g. burnout) is an individual's sense of coherence (Antonovsky, 1987). For purposes of this research, the focus is on employees' sense of coherence and its possible moderating effect on the relationship between stress and burnout. Sense of coherence is a broad-band resource (Hobfoll, 2001), which is positively associated with coping with change (Fouche \& Rothmann, 2001) and negatively associated with burnout (Basson \& Rothmann, 2002).

The objective of this study was to investigate the relationship between burnout and job stress among employees of a local government in South Africa and to determine whether sense of coherence moderates the effect of job stress on burnout.

\section{Burnout, job stress and sense of coherence}

Burnout as a phenomenon was originally observed primarily among people providing human services. However, Maslach, Jackson and Leiter (1996) developed the Maslach Burnout Inventory - General Survey (MBI-GS) to measure burnout in occupational groups other than human services. According to Maslach et al. (1996), burnout includes the following dimensions: 
- Exhaustion - refers to feelings of being overextended and depleted of one's emotional and physical resources.

- Cynicism - refers to the interpersonal dimension of burnout and is a negative, callous or detached response to various aspects of the job.

- Professional efficacy - refers to the self-evaluation dimension of burnout and is a feeling of competence, productivity and achievement at work.

Exhaustion is a necessary but not sufficient criterion for burnout (Maslach, 1998). The notion of exhaustion presupposes a prior state of high arousal or overload rather than one of low arousal or underload, which implies that burnout is not a response to tedious, boring or monotonous work. However, exhaustion fails to capture a critical aspect of the relationship people have with their work. Chronic exhaustion can lead people to distance themselves emotionally and cognitively from their work, so that they are less involved with, or responsive to the needs of other people or the demands of the task. According to Maslach and Leiter (1997), distancing is such an immediate reaction to exhaustion that a strong relationship from exhaustion to cynicism is consistently found in burnout research. Furthermore, a work situation with chronic, overwhelming demands that contribute to exhaustion or cynicism is likely to erode an individual's sense of accomplishment or effectiveness. Also, it is difficult to gain a sense of efficacy when feeling exhausted or when distancing oneself mentally from a job. In some situations the lack of efficacy seems to arise more clearly from a lack of relevant resources, while exhaustion and cynicism appears from the presence of work overload and social conflict (Maslach \& Leiter, 1997).

Job stressors are the main contributors to burnout of employees (Schaufeli \& Enzmann, 1998). Various models exist that can be used to conceptualise job stress. In the Person-Environment Fit theory (French, Caplan \& Harrison, 1992) stress in work settings is attributed to the interaction of an individual with his or her work environment. The Job Demand-Control Model (Karasek \& Theorell, 1990) focuses on the interactions between the pressures of the work environment and the decision scope of the employee in fulfilling the requirements of a job. These two models give less attention to how specific job pressures interact with individual differences in personality and coping resources to influence the emotional reactions of employees.

A major difference in the theories of job stress resides in how workplace stress is defined and measured. According to Spielberger and Vagg (1999), a comprehensive assessment of job stress requires an evaluation of the specific aspects of one's job which produce job strain. Such stressors include work overload (Corrigan et al., 1994; Landsbergis, 1988), poor collegial support (Golembiewski \& Munzenrider, 1988), role conflict and role ambiguity (Miller, Ellis, Zook \& Lyles, 1990), and lack of feedback (participation in decision-making and autonomy).

According to Schaufeli and Enzmann (1998), organizational stressors can be divided into two groups, namely job demands and a lack of job resources. Also, a factor analysis of the "Job Stress Survey" (Spielberger \& Vagg, 1999) showed that job stress can be subdivided into two components: job pressure (i.e. job demands) and lack of organizational support (i.e. lack of job resources). Job demands refer to those aspects of the job that require sustained physical or mental effort and are therefore associated with certain physiological and psychological costs. Job resources refer to those aspects of the job that may be functional in achieving work goals, reduce job demands at the associated physiological and psychological costs, and stimulate personal growth and development (Demerouti, Bakker, Nachreiner \& Schaufeli, 2001).

Taris, Schreurs and Schaufeli (1999) found that job demands were more strongly related to exhaustion than to cynicism or professional efficacy. Cynicism and professional efficacy were related to the resource variables. Peeters and Le Blanc (2001) found that organisational demands relate only to exhaustion. Janssen, Schaufeli and Houkes (1999) found that exhaustion is significantly and most strongly associated with job demands. Cynicism and professional efficacy were strongly associated with job resources, but not more so than exhaustion. Schaufeli and Enzmann (1998) analyzed 27 published studies and found that job demands clearly correlate most strongly with exhaustion and least with professional efficacy.

According to Lazarus and Folkman (1984), job stress occurs when job demands tax or exceed the person's adaptive resources. Stress is thus a generic term that refers to the temporary adaptation process that is accompanied by mental and physical symptoms and is caused by an imbalance between job demands and the response capability of the worker. In contrast, burnout can be considered as a final stage in a breakdown in adaptation that results from the long-term imbalance of demands and resources and is accompanied by chronic malfunctioning at work.

An individual's sense of coherence may either alleviate or aggravate his or her reactions towards a stressor. Antonovsky (1991) defined the concept of sense of coherence as "... a global orientation that expresses the extent to which one has a pervasive, enduring though dynamic feeling of confidence that (1) the stimuli deriving from one's internal and external environments in the course of living are structured, predictable and explicable; (2) the resources are available to one to meet the demands posed by these stimuli; and (3) these demands are challenges, worthy of investment and engagement" (Antonovsky, 1991). The definition of sense of coherence includes three dimensions that represent the concept, namely comprehensibility, manageability and meaningfulness (Antonovsky, 1987).

- Comprehensibility refers to the extent to which one perceives stimuli from the internal and external environment as information that is ordered, structured and consistent. The stimuli are perceived as comprehensible and make sense on a cognitive level.

- Manageability refers to the extent to which individuals experience events in life as situations that are endurable or manageable, or even as new challenges.

- Meaningfulness refers to the extent to which one feels that life is making sense on an emotional and not just a cognitive level.

Sense of coherence is developed as a single dimension of the individual's personality, consisting of the abovementioned interwoven components (Antonovsky 1991). It is developed through the process of coming to understanding one's life experiences and is thus rooted in the particular historical and socio-cultural context of the individual's life span. Whether a strong or a weak sense of coherence develops depends on the availability of generalised resistance resources. A strong sense of coherence will develop over time, provided that generalised resistance resources which allow repeated, consistent experiences are present, that there is a balance between overload and underload and that the outcome can be influenced. Experiences that are characterised by unpredictability, uncontrollability and uncertainty will lead to a weak sense of coherence.

Sense of coherence is a coping resource that is presumed to mitigate life stress by affecting the overall quality of one's cognitive and emotional appraisal of the stimuli that impact on one. A strong sense of coherence is negatively related to measures of negative affectivity, such as anxiety and neuroticism (Flannery \& Flannery, 1990; Frenz, Carey \& Jorgenson, 1993) and job stress (Feldt, 1997). A strong sense of coherence is also related to competence and life satisfaction (Kalimo \& Vuori, 1990), general well-being (Feldt, 1997), emotional stability (Mlonzi \& Strümpfer, 1998) and successful coping with life stress (McSherry \& Holm, 1994). 
Levert, Lucas and Ortlepp (2000) reported significant correlations between two components of burnout (exhaustion and depersonalisation) and sense of coherence in a group of psychiatric nurses in South Africa. Gilbar (1998) found significant correlations between social workers' sense of coherence and exhaustion $(r=-0,30)$, as well as their sense of coherence and personal accomplishment $(r=-0,34)$. Rothmann, Malan and Rothmann (2001) also found significant correlations between sense of coherence and exhaustion $(-0,56)$, depersonalisation $(-0,41)$ and personal accomplishment $(0,48)$. Strümpfer (1990) indicated that an individual with a strong sense of coherence will be able to understand the nature and dimensions of an acute stressor and will be able to cope through applying resources within that individual or other individuals' control rather than becoming helpless.

In summary, although sense of coherence was defined as a relatively stable dispositional orientation (Antonovsky, 1987), it is possible that job stress during major organisational change will impact on employees' sense of coherence. However, a strong sense of coherence might help employees to understand stressors, and to regard them as manageable and meaningful. Therefore, a sense of coherence might moderate the effects of job stressors on exhaustion. Exhaustion is expected to mediate the relationship between sense of coherence and cynicism. Also, sense of coherence is expected to contribute to professional efficacy of employees.

\section{METHOD}

Research design

A survey design was used to achieve the research objective. The specific design was the cross-sectional survey design, by means of which a sample is drawn from a population at a particular point in time (Shaughnessy \& Zechmeister, 1997).

\section{Participants}

The participants were employees of a local government in the North West Province in South Africa $(N=500)$. A total of 300 questionnaires were received back. However, only 267 questionnaires could be used. The mean age of participants was 37,77 and they had an average of 9,13 years of service. The characteristics of the participants are shown in Table 1 .

\section{Measuring instruments}

The following measuring instruments were used in this study:

- The Maslach Burnout Inventory - General Survey (MBI-GS) (Maslach et al., 1996) was used to measure the burnout of participants. The MBI-GS consists of 16 items in three subscales, namely exhaustion, cynicism and professional efficacy. Together the sub-scales of the MBI-GS provide a three-dimensional perspective on burnout. Internal consistencies (Cronbach coefficient alphas) reported by Maslach et al. (1996) varied from 0,87 to 0,89 for exhaustion, 0,73 to 0,84 for cynicism and 0,76 to 0,84 for professional efficacy. Test-retest reliabilities after one year were 0,65 (exhaustion), 0,60 (cynicism) and 0,67 (professional efficacy) (Maslach et al., 1996). The MBI-GS was consistently related to other constructs, as expected (Maslach et al., 1996). High scores on exhaustion and cynicism and low scores on professional efficacy are indicative for burnout.

- The Job Stress Indicator (JSI) was used to assess the sources of job stress. The JSI consists of 30 items describing job-related stressors. In line with previous research (Spielberger \& Vagg, 1999) this study addressed both the severity and frequency of stressors. Firstly, participants rated each of 30 items regarding the intensity of stress on a 9-point scale. Secondly, the frequency part of the questionnaire asked "how many times in the last six months" the source of stress had been experienced. The JSI focuses on aspects of work situations that often result in psychological strain. The items represent two categories, namely job demands and lack of organisational support.

- The Orientation to Life Questionnaire (OLQ) (Antonovsky, 1987) was used to measure participants' sense of coherence. The OLQ consists of 29 items. Antonovsky (1993) reported alpha coefficients of the OLQ in 29 research studies varying between 0,85 and 0,91 . Test-retest reliability studies found coefficients between 0,41 and 0,97 (Antonovsky, 1993). Rothmann (2000) reported an alpha coefficient of 0,89 for the OLQ, which may be regarded as acceptable (Nunnally \& Bernstein, 1994). Regarding the construct validity of the OLQ, it was found that there is a negative relationship between the OLQ and experienced stress, and that the OLQ correlates negatively with the "State-Trait Anxiety Inventory-Trait" and the "Beck Depression Inventory" (Frenz et al., 1993).

TABLE 1

Characteristics of THE Participants

\begin{tabular}{|c|c|c|}
\hline Item & Category & Percentage \\
\hline \multirow[t]{4}{*}{ Service } & $0-5$ years & 32,43 \\
\hline & $6-10$ years & 32,85 \\
\hline & $11-20$ years & 27,79 \\
\hline & More than 20 years & 6,95 \\
\hline \multirow[t]{3}{*}{ Job levels } & $1-7$ & 17,96 \\
\hline & $8-12$ & 75,27 \\
\hline & $13-18$ & 16,78 \\
\hline \multirow[t]{4}{*}{ Race } & White & 57,46 \\
\hline & Black & 30,97 \\
\hline & Coloured & 10,45 \\
\hline & Indian & 1,12 \\
\hline \multirow[t]{2}{*}{ Sex } & Male & 47,92 \\
\hline & Female & 52,08 \\
\hline \multirow[t]{2}{*}{ Marital Status } & Married & 65,67 \\
\hline & Unmarried & 34,33 \\
\hline \multirow[t]{4}{*}{ Secondary Qualifications } & Lower than Standard 8/Grade 10 & 9,34 \\
\hline & Standard $8 /$ Grade 10 & 9,73 \\
\hline & Standard 9/Grade 11 & 5,45 \\
\hline & Standard $10 /$ Grade 12 & 75,49 \\
\hline \multirow[t]{4}{*}{ Tertiary Qualifications } & Certificate & 33,33 \\
\hline & Diploma & 37,78 \\
\hline & Degree & 13,89 \\
\hline & Post-graduate & 10,00 \\
\hline \multirow[t]{9}{*}{ Directorates } & Office of the Mayor & 3,57 \\
\hline & Corporate Services & 19,05 \\
\hline & Financial Services & 3,57 \\
\hline & Public Safety & 28,57 \\
\hline & Local Economic Development & 1,79 \\
\hline & Social Services & 29,76 \\
\hline & Health \& Environmental Services & 7,74 \\
\hline & Infrastructure & 2,38 \\
\hline & Housing & 3,57 \\
\hline
\end{tabular}

\section{Statistical analysis}

The statistical analysis was carried out with the help of the SAS program (SAS Institute, 2000). Principal factors extraction with varimax rotation was performed through SAS FACTOR on 30 items of the JSI for a sample of 267. Principal components extraction was used prior to principal factors extraction to estimate the number of factors, presence of outliers and factorability of the correlation matrices. Cronbach alpha coefficients and inter-item correlations were used to assess the 
internal consistency of the measuring instruments (Clark \& Watson, 1995). Descriptive statistics (e.g. means, standard deviations, skewness and kurtosis) were used to analyse the data. Canonical correlation $\left(r_{\mathrm{c}}\right)$ was used to determine the relationships between the dimensions of burnout, job stress and sense of coherence. The goal of canonical correlation is to analyse the relationship between two sets of variables (Tabachnick \& Fidell, 2001).

Structural equation modelling (SEM) methods as implemented by AMOS (Arbuckle, 1997) were used to test the factorial model for the MBI-GS, using the maximum likelihood method. Hypothesised relationships are tested empirically for goodness of fit with the sample data. The $\chi^{2}$ statistic and several other goodness-of-fit indices summarise the degree of correspondence between the implied and observed covariance matrices. Jöreskog and Sörbom (1993) suggest that the $\chi^{2}$ value may be considered more appropriately as a badness-of-fit rather than as a goodnessof-fit measure in the sense that a small $\chi^{2}$ value is indicative of good fit. However, because the $\chi^{2}$ statistic equals $(\mathrm{N}-1) \mathrm{F}_{\min }$ this value tends to be substantial when the model does not hold and the sample size is large (Byrne, 2001). A large $\chi^{2}$ relative to the degrees of freedom indicates a need to modify the model to fit the data better. Researchers have addressed the $\chi^{2}$ limitations by developing goodness-of-fit indexes that take a more pragmatic approach to the evaluation process. These criteria, commonly referred to as "subjective" or "practical" indexes of fit, are typically used as adjuncts to the $\chi^{2}$ statistic.

The Goodness of Fit Index (GFI) indicates the relative amount of the variances/co-variances in the sample predicted by the estimates of the population. A value of 0,90 or above indicates a good model fit. In addition, the Adjusted Goodness-of-Fit Index (AGFI) is given. The AGFI is a measure of the relative amount of variance accounted for by the model, corrected for the degrees of freedom in the model relative to the number of variables $\mathrm{Hu}$ \& Bentler, 1995). The parsimony goodness-of-fit index (PGFI) addresses the issue of parsimony in SEM (Mulaik et al., 1989). The PGFI takes into account the complexity (i.e., number of estimated parameters) of the hypothesised model in the assessment of overall model fit and provides a more realistic evaluation of the hypothesised model. Mulaik et al. (1989) suggested that indices in the 0,90 's accompanied by PGFIs in the 0,50 's are not unexpected, however, values $>0,80$ are considered to be more appropriate (Byrne, 2001).

The Normed Fit Index (NFI) is used to assess global model fit. The NFI represents the point at which the model being evaluated falls on a scale running from a null model to perfect fit. Marsh, Balla and Hau (1996) suggest that this index is relatively insensitive to sample sizes. The Comparative Fit Index (CFI) represents the class of incremental fit indices in that it is derived from the comparison of a restricted model (i.e., one in which structure is imposed on the data) with that of an independence (or null) model (i.e., one in which all correlations among variables are zero) in the determination of goodness-of-fit. The Tucker-Lewis Index (TLI; Tucker \& Lewis, 1973) is a relative measure of covariation explained by the model that is specifically developed to assess factor models. For these fit indices (NFI, CFI and TLI), it is more or less generally accepted that a value of less than 0,90 indicates that the fit of the model can be improved (Hoyle, 1995).

To overcome the problem of sample size, Browne and Cudeck (1993) suggested using the Root Mean Square Error of Approximation (RMSEA) and the $90 \%$ confidence interval of the RMSEA. The RMSEA estimates the overall amount of error; it is a function of the fitting function value relative to the degrees of freedom. The RMSEA point estimate should be 0,05 or less and the upper limit of the confidence interval should not exceed 0,08 . Hu and Bentler (1999) suggested a value of 0,06 to be indicative of good fit between the hypothesised model and the observed data. MacCallum, Browne, and Sugawara, (1996) recently elaborated on these cut-off points and noted that RMSEA values ranging from 0,08 to 0,10 indicate mediocre fit, and those greater than 0,10 indicate poor fit.

\section{RESULTS}

Data analyses for the test of the factorial validity of the MBI-GS proceeded as follows: First, a quick overview of model fit was done by looking at the overall ( 2 value, together with its degrees of freedom and probability value. Global assessments of model fit were based on several goodness-of-fit statistics (GFI, AGFI, PGFI, NFI, TLI, CFI and RMSEA); secondly, given findings of an ill-fitting initially hypothesised model, analyses proceeded in an exploratory mode. Possible misspecifications as suggested by the so-called modification indices were looked for, and eventually a revised, re-specified model was fitted to the data.

\section{Hypothesised model}

The full hypothesised 3-factor model consisting of all 16 items was tested (see Figure 1). Table 2 presents fit statistics for the test of the original model.

\section{TABle 2}

GOODNESS-OF-FIT STATISTICS FOR THE HYPOTHESISED MBI- GS MODEL

\begin{tabular}{lccccccccc}
\hline Model & $\chi^{2}$ & $\chi^{2} / \mathrm{df}$ & GFI & AGFI & PGFI & NFI & TLI & CFI & RMSEA \\
\hline Model 1 & 300,98 & 2,98 & 0,87 & 0,82 & 0,64 & 0,78 & 0,81 & 0,84 & 0,09 \\
Model 2 & 251,76 & 2,89 & 0,88 & 0,84 & 0,64 & 0,81 & 0,84 & 0,86 & 0,09 \\
Model 3 & 197,07 & 2,29 & 0,91 & 0,88 & 0,65 & 0,85 & 0,89 & 0,91 & 0,07 \\
\hline
\end{tabular}

The statistically significant $\chi^{2}(101)=300,98(p<0,00)$ revealed a relatively poor overall fit of the originally hypothesised MBI model. However, both the sensitivity of the likelihood ration test to sample size and its basis on the central $\chi^{2}$ distribution, which assumes that the model fits perfectly in the population, have been reported to lead to problems of fit (Jöreskog \& Sörbom, 1993). Furthermore, the hypothesised model (Model 1) was also not that good from a practical perspective. The PGFI value lower than 0,80 , NFI, TLI and CFI values lower than 0,95 and RMSEA value higher than 0,05 are indicative of failure to confirm the hypothesised model.

To pinpoint possible areas of misfit, standardised residuals values were examined. Standardised residuals are fitted residuals divided by their asymptotically (large sample) standard errors (Jöreskog \& Sörbom, 1988). In essence, they represent estimates of the number of standard deviations the observed residuals are from the zero residuals that would exist if model fit were perfect (Byrne, 2001). Values > 2,58 are considered to be large (Jöreskog \& Sörbom, 1988).

\section{Post hoc analyses}

Given rejection of the initially postulated 3 -factor model, the focus shifted from model test to model development (exploratory factor analysis). Considering the high standardised residuals of one item, it was decided to re-specify the model with Item 13 deleted. All subsequent analyses are now based on the 15 -item revision, which is labelled here as Model 2. The fit statistics are presented in Table 2.

Although the various fit indexes for this model are substantially improved compared to those for the initial model, there is still some evidence of misfit in the model. For example, the $\chi^{2}(87)=$ $251,76(p<0,00)$ was still statistically significant, while the PGFI and RMSEA values were only marginally adequate. Modification indexes (MI) were considered to pinpoint areas of misspecification in the model. The constrained parameters 
exhibiting the highest degree of misfit lay in the error covariance matrix and represent a correlated error between Item 11 and Item $12(\mathrm{MI}=49,42)$. Compared with MI values for all other error covariance parameters, this value is exceptionally high and clearly in need of re-specification. Based on the modification indices and on theoretical considerations, Model 2 was re-specified, with these parameters freely estimated. Following Byrne (2001), errors of one item pair (i.e. Item 11 and Item 12) were allowed to correlate. Table 2 summarises the goodness-of-fit statistics of Model 3.

The fit statistics in Table 2 indicate a relatively good fit for the respecified model. Although the $\chi^{2}(86)=197,07(p<0,00)$ is still high, it is considerably lower than in Model 1 . All the other fit statistics indicate good fit of the measurement model to the data. Since this model fit was satisfactory and the results agreed with the theoretical assumptions underlying the structure of the MBIGS, no further modifications of the model were deemed necessary. The correlations between the three burnout dimensions are as follows: Exhaustion and cynicism show the highest correlation of 0,71 , followed by cynicism and professional efficacy with a correlation of $-0,29$, and exhaustion and professional efficacy with a correlation of $-0,14$, respectively.

TABLE 3

Factor loadings, COMmunalities (h2), PerCentage VarianCe AND COVARIANCE FOR OBLIQUE FACTORS EXTRACTION AND PROMAX ROTATION ON JOB STRESS ITEMS

\begin{tabular}{llll}
\hline & $\boldsymbol{F}_{1}^{\mathrm{a}}$ & $\boldsymbol{F}_{2}$ & $\boldsymbol{h}^{2}$ \\
\hline Meeting deadlines & 0,68 & 0,00 & 0,46 \\
Making critical decisions & 0,65 & 0,00 & 0,43 \\
Excessive paperwork & 0,61 & 0,00 & 0,37 \\
Dealing with crisis situations & 0,61 & 0,00 & 0,34 \\
Covering work for others & 0,60 & 0,00 & 0,36 \\
Changes from boring to demanding activities & 0,59 & 0,00 & 0,37 \\
Working overtime & 0,56 & 0,00 & 0,32 \\
Assignment of increased responsibility & 0,53 & 0,00 & 0,30 \\
Assignment of unfamiliar duties & 0,53 & 0,00 & 0,29 \\
Performing tasks not in job description & 0,53 & 0,00 & 0,28 \\
Interruptions & 0,51 & 0,00 & 0,28 \\
Insufficient personnel to handle assignment & 0,50 & 0,00 & 0,31 \\
Insufficient personal time & 0,48 & 0,00 & 0,23 \\
Assignment of disagreeable duties & 0,44 & 0,00 & 0,23 \\
Difficulty to get along with supervisor & 0,00 & 0,63 & 0,40 \\
Lack of supervisor support & 0,00 & 0,62 & 0,39 \\
Poorly motivated workers & 0,00 & 0,63 & 0,42 \\
Fellow workers not doing their job & 0,00 & 0,59 & 0,36 \\
Negative attitudes towards local council & 0,00 & 0,56 & 0,32 \\
Inadequate supervision & 0,00 & 0,55 & 0,32 \\
Poor/inadequate equipment & 0,00 & 0,50 & 0,26 \\
Personal insult from customer/colleague & 0,00 & 0,52 & 0,34 \\
Inadequate salary & 0,00 & 0,49 & 0,26 \\
Competition for advancement & 0,00 & 0,48 & 0,25 \\
Periods of inactivity & 0,00 & 0,46 & 0,21 \\
Conflicts with other departments & 0,00 & 0,46 & 0,29 \\
Lack of recognition & 0,00 & 0,45 & 0,22 \\
Lack of participation in policy-making decisions & 0,00 & 0,43 & 0,22 \\
Lack of opportunity for advancement & 0,00 & 0,40 & 0,16
\end{tabular}

\begin{tabular}{|l|c|c|}
\hline Squared Multiple Correlation (SMC) & 0,86 & 0,84 \\
\hline Percentage variance & 21,03 & 19,33 \\
\hline Percentage covariance & 52,10 & 47,90 \\
\hline
\end{tabular}

a Factor labels:

$\mathrm{F}_{1}$ Job Demands

$\mathrm{F}_{2}$ Lack of Organisational Support
The results of the factor analysis for the JSI are shown in Table 3. Loadings of variables on factors, communalities and percent of variance and covariance are shown in Table 3 . Variables are ordered and grouped by size of loading to facilitate interpretation. Loadings under 0,45 (20\% of variance) are replaced by zeros. Labels are suggested for each factor in a footnote.

Principal components extraction through SAS FACTOR was used in an initial run to estimate the number of factors of the JSI from eigenvalues. Three factors with eigenvalues larger than one were obtained, but the scree plot showed a sharp break after the second factor. Inspection of Table 3 shows that two factors were extracted. As indicated by the SMCs, both factors were internally consistent and well defined by the variables. Communality values, as seen in Table 3 , tended to be moderate to low. With a cut of 0,45 for inclusion of a variable in the interpretation of a factor, 29 of 30 variables did load on the two factors.

When oblique rotation was requested, factors interpreted as Job Demands and Lack of Organisational Support correlated 0,44. An oblique rotation (using Promax) was subsequently carried out on the two factors.

The descriptive statistics, alpha coefficients and inter-item correlations of the MBI-GS, OLQ and JSI are given in Table 4.

\section{TABLe 4}

DESCRIPTIVE STATISTICS, ALPHA COEFFICIENTS AND INTER-ITEM CORRELATIONS OF THE MEASURING INSTRUMENTS

\begin{tabular}{lrrrrrr}
\hline Item & Mean & $S D$ & Skewness & Kurtosis & $\boldsymbol{r}$ (Mean) & $\alpha$ \\
\hline Burnout & & & & & & \\
Exhaustion & 11,92 & 7,77 & 0,46 & $-0,63$ & 0,55 & 0,86 \\
Cynicism & 7,17 & 5,68 & 0,60 & $-0,57$ & 0,39 & 0,72 \\
Professional Efficacy & 28,34 & 6,42 & $-0,84$ & $-0,07$ & 0,26 & 0,68 \\
Sense of Coherence & & & & & & \\
OLQ & 135,92 & 21,37 & 0,35 & $-0,34$ & 0,15 & 0,80 \\
Job Stress & & & & & & \\
Job Demands & 67,35 & 19,48 & $-0,07$ & $-0,07$ & 0,32 & 0,87 \\
Lack of Organisational & 74,74 & 20,32 & 0,05 & $-0,28$ & 0,28 & 0,86 \\
Support & & & & & & \\
\hline
\end{tabular}

The scores of all the scales are normally distributed. The Cronbach alpha coefficients of all the scales in Table 4 are considered to be acceptable compared to the guideline of $\alpha>0,70$ (Nunnally \& Bernstein, 1994). Furthermore, the inter-item correlations are considered acceptable compared to the guideline of $0,15<r<0,50$ (Clark \& Watson, 1995). It appears that the scales have acceptable levels of internal consistency.

The severity of job stressors in the local government is reported in Table 4. For the purposes of this study the severity of a stressor was regarded as a product of its intensity and frequency of occurrence.

Table 4 shows that poor or inadequate equipment, inadequate salary, a lack of opportunity for advancement, poorly motivated co-workers, a lack of recognition, insufficient personnel to handle assignments and performing tasks not in the job descriptions were regarded as the most severe stressors.

The product-moment correlation coefficients between burnout, stress and sense of coherence are given in Table 5 . 
TABLE 5

SEVERITY OF STRESSORS IN THE CITY COUNCIL

\begin{tabular}{lccc}
\hline & Intensity & Frequency & Severity \\
\hline JOB DEMANDS & & & \\
Meeting deadlines & 4,64 & 4,68 & 21,72 \\
Making critical decisions & 4,86 & 4,24 & 20,52 \\
Excessive paperwork & 4,52 & 4,43 & 19,57 \\
Dealing with crisis situations & 5,13 & 4,43 & 22,73 \\
Covering work for others & 4,91 & 5,03 & 24,70 \\
Changes from boring to & 4,26 & 4,26 & 18,15 \\
demanding activities & & & \\
Working overtime & 4,07 & 4,69 & 19,09 \\
Assignment of increased responsibility & 4,82 & 4,79 & 23,09 \\
Assignment of unfamiliar duties & 4,64 & 4,27 & 19,81 \\
Performing tasks not in job description & 5,19 & 5,22 & 27,09 \\
Interruptions & 4,90 & 4,73 & 23,18 \\
Insufficient personnel to handle & 5,96 & 5,57 & 33,20 \\
assignment & & & \\
Insufficient personal time & 4,63 & 4,53 & 20,97 \\
Assignment of disagreeable duties & 4,82 & 3,55 & 17,11 \\
& & & \\
LACK OF ORGANISATIONAL SUPPORT & & & \\
Difficulty to get along with supervisor & 4,05 & 3,06 & 13,39 \\
Inadequate support by supervisor & 5,03 & 4,24 & 21,33 \\
Poorly motivated co-workers & 5,56 & 5,16 & 28,69 \\
Fellow workers not doing their job & 5,28 & 4,93 & 26,03 \\
Negative attitudes towards local council & 4,79 & 4,03 & 19,30 \\
Poor or inadequate supervision & 4,39 & 3,53 & 15,50 \\
Poor or inadequate equipment & 5,50 & 5,65 & 31,08 \\
Personal insult from customer/colleague & 5,13 & 4,53 & 23,24 \\
Inadequate salary & 6,03 & 5,19 & 31,30 \\
Competition for advancement & 4,85 & 3,79 & 18,38 \\
Periods of inactivity & 3,96 & 2,67 & 10,57 \\
Conflicts with other departments & 4,16 & 2,97 & 12,36 \\
Lack of recognition & 5,26 & 5,09 & 26,77 \\
Lack of participation in & 4,93 & 4,27 & 21,05 \\
policy-making decisions & & & \\
Lack of opportunity for advancement & 5,89 & 4,94 & 29,10 \\
\hline & & & \\
\hline
\end{tabular}

Inspection of Table 6 shows that exhaustion is negatively related to sense of coherence and positively related to job demands and a lack of organisational support (all medium effects).

TABLE 6

Product-Moment Correlation COefFicients BetWeen BURNOUT, STRESS AND SENSE OF COHERENCE

\begin{tabular}{lccccc}
\hline & OLQ & Exhaustion & $\begin{array}{c}\text { Cynicism } \\
\text { Efficacy }\end{array}$ & $\begin{array}{c}\text { Professional } \\
\text { Demands }\end{array}$ & Job \\
\hline Exhaustion & $-0,32 *$ & - & - & - & - \\
Cynicism & $-0,27$ & $0,57 * *$ & - & - & - \\
Professional Efficacy & 0,28 & $-0,08$ & $-0,27$ & - & - \\
Job Demands & $-0,28$ & $0,47 *$ & 0,23 & $-0,14$ & - \\
$\begin{array}{l}\text { Lack of Organisational } \\
\text { Support }\end{array}$ & $-0,19$ & $0,41 *$ & 0,27 & $-0,10$ & $0,62 *$ \\
\hline
\end{tabular}

* Correlation is practically significant $r>0,30$ (medium effect)

** Correlation is practically significant $r>0,50$ (large effect)

Canonical correlation was performed between a set of stressors and burnout using SAS CANCORR. Shown in the tables are correlations between the variables and canonical variates, standardised canonical variate coefficients, within-set variance accounted for by the canonical variates (percent of variance), redundancies and canonical correlations.

The results of the canonical analysis of stressors, sense of coherence and burnout are shown in Table 7.

TABLE 7

RESULTS OF THE CANONICAL ANALYSIS: SENSE OF COHERENCE, JOB STRESS AND BURNOUT

\begin{tabular}{lcccc}
\hline & \multicolumn{3}{c}{ First Canonical Variate } \\
\hline & \multicolumn{2}{c}{ Variate 1} & \multicolumn{2}{c}{ Variate 2} \\
\hline Stressor Set & $-0,69$ & $-0,49$ & 0,70 & 0,90 \\
Sense of Coherence & 0,85 & 0,52 & 0,50 & 0,76 \\
Job Demands & 0,72 & 0,30 & 0,28 & $-0,03$ \\
Lack of Organisational Support & 0,57 & & 0,27 & \\
Percentage Variance & 0,18 & & 0,01 & \\
Redundancy & & & & 0,70 \\
Burnout Set & 0,94 & 0,92 & 0,29 & $-0,62$ \\
Exhaustion & 0,60 & $-0,02$ & $-0,41$ & 0,68 \\
Cynicism & $-0,42$ & $-0,35$ & 0,79 & \\
Professional Efficacy & 0,47 & & 0,29 & \\
Percentage Variance & 0,15 & & 0,01 & \\
Redundancy & 0,56 & & 0,19 & \\
Canonical Correlation & & & &
\end{tabular}

The first canonical correlation was 0,56 (31\% overlapping variance). With all three canonical correlations included, $F(9,642,66)=13,67, p<0,0001$. The second correlation was $0,19, F(4,530)=3,40,(p<0,01)$. Subsequent F-tests were not statistically significant $(p<0,0001)$. Therefore the first two pairs of canonical variates accounted for the significant relationships between the two sets of variables. However, interpretation of the second canonical variate is questionable because of the relatively small percentage of variance shared by the two sets in the variate (Tabachnick \& Fidell, 2002). The first canonical variate, therefore, accounted for the significant relationship between the two sets of variables. Total percent of variance and total redundancy indicate that the canonical variates were moderately related.

With a cut-off correlation of 0,30 the variables in the stressor set that correlated with the first canonical variate were sense of coherence, job demands and lack of organisational support. Among the burnout variables, exhaustion, cynicism and professional efficacy correlated with the first canonical variate. The first pair of canonical variates indicates that sense of coherence $(-0,69)$, pressures of job demands $(0,85)$ and lack of organisational support $(0,72)$ are associated with exhaustion $(0,94)$, cynicism $(0,60)$ and low professional efficacy $(-0,42)$.

The proposed model including hypothesized relationships was tested with SEM analysis. Results indicated that that the model did fit adequately to the data, $\chi^{2}(6)=15,26$, GFI $=0,98$, RMSEA $=0,07, \mathrm{CFI}=0,98, \mathrm{IFI}=0,98$, and TLI $=0,96$. Inspection of the modification indices revealed that the fit between the model and the data could be further improved if covariation was allowed between the measurement errors of two burnout dimensions. It is important to note that items with identical rating scales often have measurement errors that are correlated (Byrne, 1989). This means that the fit of the proposed model can be improved if the measurement errors among the items of the subscales are considered. The revised model - including the covariation - shows a good fit, $\chi^{2}(6)=8,99$, GFI $=0,99$, RMSEA $=0,05$, CFI $=0,99$, IFI $=0,99$, and TLI $=0,98$. The final model is given in Figure 1. 


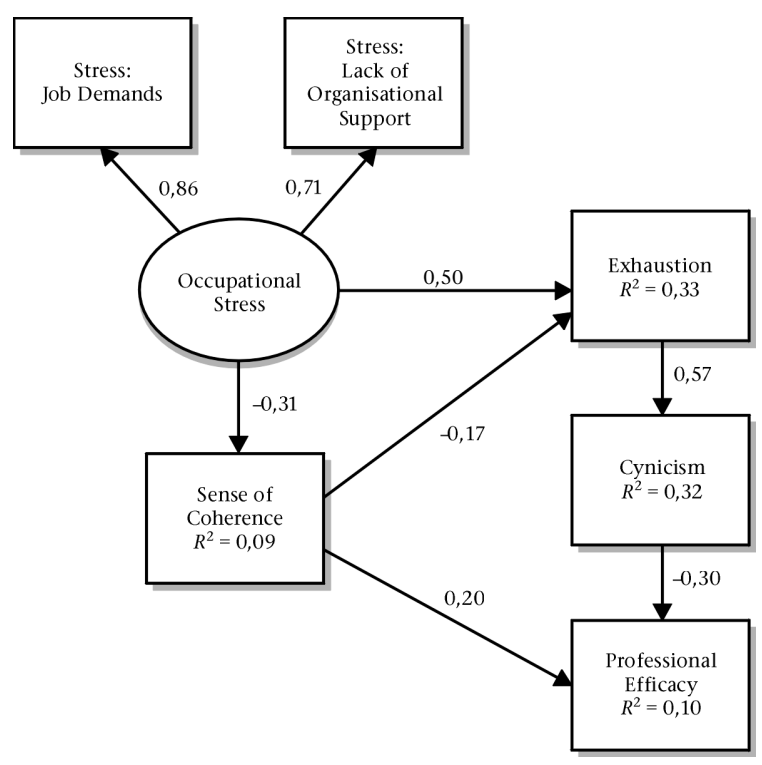

Figure 1. Maximum likelihood estimates for the burnout model, $\mathrm{N}=270$. Note. All factor loadings and path coefficients are significant at the $p<0,01$ level

As can be seen in Figure 1, the path from job stress to exhaustion is significant. This means that the higher the stress because of job demands and a lack of organizational support reported by employees, the higher their level of exhaustion. In addition, the path coefficients from sense of coherence to exhaustion and professional efficacy were significant. This means that the higher the sense of coherence, the lower the exhaustion and the higher the professional efficacy.

Given that the paths from job stress to exhaustion and sense of coherence are significant and that the path from sense of coherence to exhaustion is also significant, it could be deduced that sense of coherence moderates the effect of job stress on exhaustion. Furthermore, Figure 1 shows that the paths from exhaustion to cynicism and from cynicism to professional efficacy were significant. Therefore, higher exhaustion coincided with higher cynicism, while higher cynicism coincided with lower professional efficacy. Lastly, the paths from job stress to sense of coherence, and from sense of coherence to professional efficacy were significant. This suggests that sense of coherence mediates the effects of job stress on professional efficacy.

\section{DISCUSSION}

Regarding job stress, the two extracted factors (job demands and lack of organisational support) support previous research (Spielberger \& Vagg, 1999) regarding stressors in organisational environments. Item scores on the JSI indicated that insufficient personnel to handle assignments, performing tasks not in the job description and covering tasks for others were the most severe stressors associated with job demands. These stressors are possibly the result of the transformation process in the local government. Stress because of a lack of organisational support was attributed to an inadequate salary, a lack of opportunity for advancement, poorly motivated workers and fellow workers not doing their jobs. Combined with stressful job demands, stress related to a lack of organisational support (which included the most severe stressors), could result in perceptions of a lack of reciprocity, which will contribute to burnout (Schaufeli \& Enzmann, 1998).

The results of the canonical analysis in this study showed that sense of coherence combined with job stressors are related to exhaustion, cynicism and professional efficacy. This finding confirms the results of Basson and Rothmann (2002) and Wissing, De Waal and De Beer (1992). Sense of coherence, job demands, and a lack of organisational support were strongly related to exhaustion (33\% of the variance explained), while cynicism was strongly related to exhaustion (32\% of the variance explained). The causal model showed that exhaustion mediates the relationship between job stress and sense of coherence on the one hand, and cynicism on the other hand. Furthermore, sense of coherence and cynicism were moderately related to professional efficacy ( $10 \%$ of the variance explained). Cynicism mediated the relationship between exhaustion and professional efficacy. This confirmed the findings of Maslach and Leiter (1997) that a work situation with overwhelming demands that contribute to exhaustion. In addition, it seems that exhaustion and cynicism erodes an individual's professional efficacy.

The structural model showed that sense of coherence moderated the effect of job stress on exhaustion. Job stress (i.e. because of job demands and a lack of organisational support) had a direct negative effect on exhaustion. While the path from job stress to exhaustion was significantly positive and the path from job stress to sense of coherence was significantly negative, the path from sense of coherence to exhaustion was significantly negative. This means that job stress impacts on exhaustion and sense of coherence, but that a strong sense of coherence moderates the effect of job stress on exhaustion. The results suggest that the effect of exhaustion on professional efficacy is mediated by cynicism, while the effect of job stress on professional efficacy is mediated by sense of coherence. This means that low professional efficacy result because of a weak sense of coherence and high cynicism. Accordingly, it seems that sense of coherence reduce the effects of job stress on exhaustion. Sense of coherence also protects the employee from developing low professional self-efficacy.

Employees with a strong sense of coherence experience less exhaustion because stimuli from the environment are perceived as making cognitive sense, as under the control of both the individual and legitimate others and as motivationally relevant and meaningful. According to Hobfoll (2001), burnout results when individuals fail to acquire sufficient resources. Two interpretations are possible of the relation between a weak sense of coherence and burnout. Firstly, individuals with better and more resources are less vulnerable to resource loss and more inclined to gain better resources. Conversely, those with fewer resources are more vulnerable to resource loss and are less able to gain resources. Sense of coherence is regarded as a broad-band resource, while burnout could be the result of a lack of resources. Secondly, it is possible that the sense of coherence of individuals weakens because of burnout.

Although the research design does not allow one to prove causal relationships, it seems likely that a strong sense of coherence could provide protection against burnout because it starts developing early in life outside the work environment, and burnout (if it does occur) only after an individual has been employed for some length of time (Strümpfer, 2002). A tentative conclusion is that sense of coherence, which is regarded as a "meaning-providing variable" (Strümpfer, 2002), may assist in the warding-off of burnout. Individuals with a strong sense of coherence could also experience burnout but will, in the long term, probably benefit even from that. They are likely to use the temporary condition of anguish as an opportunity for growth: for resolving pre-existing and present problems, for reorganising their life and work circumstances, and for going forward with newly discovered skills and perspectives on self and life (Strümpfer, 2002). 


\section{RECOMMENDATIONS}

The local government should attend to employees' sense of coherence, job stress and burnout. Firstly, the local government can contribute to the development of employees' sense of coherence by giving information in a consistent, structured, ordered and understandable format. Employees should further be able to identify their roles within the greater whole, and as such the comprehensibility component of sense of coherence will be enhanced. Secondly, by equipping employees with the necessary knowledge, skills, material, instruments and other resources, and by ensuring a balance in the load of tasks to be handled, the employees will increasingly feel that the work expectations are manageable and within their power or that of an important other.

Thirdly, the salary and promotion practices of the local government should be evaluated to determine whether they are appropriate to the local government's current strategy. Current practices are probably outdated and contribute to the stress and burnout of employees. Fourthly, when a degree of independence and freedom of choice in the performance of employees' tasks is allowed, employees will regard their work as meaningful. Participation in decision-making will enhance the employees' feeling of membership and contribute to the meaningfulness component of sense of coherence. As a fifth point, the employee should have the freedom to disagree with his or her supervisor, to discuss what to do with his or her supervisor (rather than to be told what to do) and to act autonomously (without being supervised too closely). Lastly, job stressors in the local government should be addressed, and specifically those related to a lack of organisational support, such as an inadequate salary, a lack of opportunity for advancement, poorly motivated workers and fellow workers not doing their jobs.

Future research should focus on burnout, job stress and sense of coherence in other local governments in South Africa. Furthermore, research is needed regarding engagement (which could be regarded as the "opposite" of burnout) in local governments. More research is needed on the validity and structural equivalence of the measuring instruments for different cultural groups in local governments.

\section{REFERENCES}

Antonovsky, A. (1987). Unravelling the mystery of health: How people manage stress and stay well. San Francisco: Jossey-Bass.

Antonovsky, A. (1991). The structural sources of salutogenic strengths. In C.L. Cooper \& R. Payne (Eds.), Personality and stress: Individual differences in the stress process. New York: Wiley.

Antonovsky, A. (1993). The structure and properties of the sense of coherence scale. Social Science and Medicine, 36, 725-733.

Arbuckle J.L. (1997). Amos users' guide version 4.0. Chicago, IL: Smallwaters Corporation.

Basson, M.J. \& Rothmann, S. (2002). Sense of coherence, coping and burnout of pharmacists. South African Journal of Economic and Management Sciences, 5 (1), 35-62.

Beehr, T. (2000). An organization psychology meta-model or occupational stress. In C.L. Cooper (Ed.), Theories of organizational stress (pp. 6-27). Oxford: University Press.

Browne, M.W. \& Cudeck, R. (1993). Alternative ways of assessing model fit. In K.A. Bollen \& J.S. Long (Eds.), Testing structural equation models (pp. 136-162). London: Sage.

Byrne, B.M. (1989). A primer of LISREL: Basic applications and programming for factor analysis models. New York: SpringerVerlag.

Byrne, B.M. (2001). Structural equation modeling with AMOS: Basic concepts, applications and programming. Mahwah, NJ: Erlbaum.

Clark, L.A. \& Watson, D. (1995). Constructing validity: Basic issues in objective scale development. Psychological Assessment, 7, 309-319.
Cooper, C.L. (2000). Theories of organizational stress. Oxford: University Press.

Corrigan, P.W., Holmes, E.P., Luchins, D., Buican, B., Basit, A.J. \& Parks, J. (1994). Staff burnout in a psychiatric hospital: A cross-lagged panel design. Journal of Organizational Behavior, $15,65-74$

Demerouti, E., Bakker, A.B., Nachreiner, F. \& Schaufeli, W.B. (2001). The job demands-resources model of burnout. Journal of Applied Psychology, 86, 499-512.

Feldt, T. (1997). The role of sense of coherence in well-being at work: Analysis of main and moderator effects. Work and Stress, 11, 134-147.

Flannery, R.B. \& Flannery, G.J. (1990). Sense of coherence, life stress, and psychological distress: A prospective methodological enquiry. Journal of Clinical Psychology, 46, 415-420.

Fouche, E. \& Rothmann, S. (2001). Bestuurders se coping met verandering: 'n Fortigene benadering. Tydskrif vir Bedryfsielkunde, 27 (1), 32-38.

Frenz, J.R.P., Caplan, R.D. \& Harrison, R.V. (1982). The mechanisms of job stress and strain. Chichester: Wiley.

Frenz, A.W., Carey, M.P. \& Jorgensen, R.S. (1993). Psychometric evaluation of Antonovsky's sense of coherence scale. Psychological Assessment, 5, 145-153.

Gilbar, O. (1998). Relationship between burnout and sense of coherence in health social workers. Social Work in Health Care, 26 (3), 39-49.

Golembiewski, R.T. \& Munzenrider, R.F. (1988). Phases of burnout: Development in concepts and applications. New York: Praeger.

Hobfoll, S.E. (2001). The influence of culture, community and the nested-self in the stress process: Advancing conservation of resources theory. Applied Psychology: An International Review, 50, 337-369.

Hoyle, R.H. (1995). The structural equation modeling approach: Basic concepts and fundamental issues. In R.H. Hoyle (Ed.), Structural equation modeling: Concepts, issues, and applications (pp. 1-15). Thousand Oaks, CA: Sage.

Hu, L.-T. \& Bentler, P.M. (1995). Evaluating model fit. In R.H. Hoyle (Ed), Structural equation modeling: Concepts, issues, and applications (pp. 76-99). Thousand Oaks, CA: Sage.

Janssen, P.P.M., Schaufeli, W.B. \& Houkes, I. (1999). Work-related and individual determinants of the three burnout dimensions. Work and Stress, 13, 74-86.

Jöreskog, K.G. \& Sörbom, D. (1988). LISREL 7: A guide to the program and applications. Chicago: SPSS, Inc.

Jöreskog, K.G. \& Sörbom, D. (1993). LISREL 8: Structural equation modeling with the SIMPLIS command language. Hillsdale, NJ: Lawrence Erlbaum Associates.

Kalimo, R. \& Vuori, J. (1990). Work and sense of coherence: Resources for competence and life satisfaction. Behavioural Medicine, 16, 76-89.

Karasek, R.A. \& Theorell, T. (1990). Healthy work: Stress, productivity, and the reconstruction of working life. New York: Basic Books.

Landsbergis, P.A. (1988). Occupational stress among health care workers: A test of the job demands-control model. Journal of Organizational Behaviour, 9, 217-239.

Lazarus, R.S. \& Folkman, S. (1984). Coping and adaptation. In W.D. Gentry (Ed.), Handbook of behavioral medicine (pp. 282325). New York: Guilford.

Levert, T., Lucas, M. \& Ortlepp, K. (2000). Burnout in psychiatric nurses: Contributions of the work environment and a sense of coherence. South African Journal of Psychology, 30, 36-43.

MacCallum, R.C., Browne, M.W. \& Sugawara, H.M. (1996). Power analysis and determination of sample size for covariance structure modeling. Psychological Methods, 1, 130-149.

Marsh, H.W., Balla, J.R. \& Hau, K.T. (1996). An evaluation of Incremental Fit Indices: A clarification of mathematical and empirical properties. In G.A. Marcoulides \& R.E. Schumacker (Eds.), Advanced structural equation modeling: Issues and techniques (pp. 315-353). Mahwah, NJ: Erlbaum. 
Maslach, C. \& Jackson, S.E. (1986). The Maslach Burnout Inventory ( $2^{\text {nd }}$ ed.). Palo Alto, CA: Consulting Psychologists Press.

Maslach, C., Jackson, S.E. \& Leiter, M. (1996). Maslach Burnout Inventory: Manual (3 ${ }^{\text {rd }}$ ed.). Palo Alto, CA: Consulting Psychologists Press.

Maslach, C. \& Leiter, M.P. (1997). The truth about burnout. San Francisco: Jossey-Bass.

MacCallum, R.C., Browne, M.W. \& Sugawara, H.M. (1996). Power analysis and determination of sample size for covariance structure modeling. Psychological Methods, 1, 130-149.

McSherry, W.C. \& Holm, J.E. (1994). Sense of coherence: Its effects on psychological and physiological processes prior to, during, and after a stressful situation. Journal of Clinical Psychology, 50, 476-487.

Miller, K.I., Ellis, B.H., Zook, E.G. \& Lyles, J.S. (1990). An integrated model of communication, stress, and burnout in the work place. Communication Research, 17, 200-326.

Mlonzi, E.N. \& Strümpfer, D.J.W. (1998). Antonovsky's sense of coherence scale and $16 \mathrm{PF}$ second-order factors. Social Behaviour and Personality, 26, 39-50.

Mulaik, S.A., James, L.R., Van Altine, J., Bennett, N., Lind, S. \& Stillwell, C.D. (1989). Evaluation of goodness-of-fit indices for structural equation models. Psychological Bulletin, 105, 430-445.

Nunnally, J.C. \& Bernstein, I.H. (1994). Psychometric theory (3 ${ }^{\text {rd }}$ ed.). New York: McGraw-Hill.

Peeters, M.C.W. \& Le Blanc, P.M. (2001). Towards a match between job demands and sources of social support: A study among oncology care providers. European Journal of Work and Organizational Psychology, 10, 53-72.

Rothmann, S. (2000, July). Sense of coherence, locus of control and job satisfaction. Paper presented at the $27^{\text {th }}$ International Congress of Psychology, Stockholm, Sweden.
Rothmann, S. (2001). Sense of coherence, locus of control, selfefficacy and job satisfaction. Journal of Economic and Management Sciences, 5 (1), 41-65.

Rothmann, S., Malan, A.M. \& Rothmann, J.C. (2001, August). Sense of coherence, coping and burnout in a corporate pharmacy group. Paper presented at the $7^{\text {th }}$ Annual PsySSA Conference, Johannesburg, RSA.

SAS Institute. (2000). The SAS System for Windows: Release 8.01. Cary, NC: SAS Institute Inc.

Schaufeli, W.B. \& Enzmann, D. (1998). The burnout companion to study and practice: A critical analysis. London: Taylor \& Francis.

Shaughnessy, J.J. \& Zechmeister, E.B. (1997). Research methods in psychology (4th ed.). New York: McGraw-Hill.

Spielberger, C.D. \& Vagg, P.R. (1999). Job Stress Survey: Professional manual. Odessa, FL: Psychological Assessment Resources, Inc.

Strümpfer, D.J.W. (1990). Salutogenesis: A new paradigm. South African Journal of Psychology, 20, 265-276.

Strümpfer, D.J.W. (2002, March). Resiling: A stitch that saves nine. Paper presented at the $1^{\text {st }}$ South African Burnout Conference, Potchefstroom.

Strümpfer, D.J.W., Danana, N., Gouws, J.F. \& Viviers, M.R (1998). Personality dispositions and job satisfaction. South African Journal of Psychology, 28, 92-100.

Tabachnick, B.G. \& Fidell, L.S. (2001). Using multivariate statistics (4th ed.). Boston, MA: Allyn \& Bacon.

Taris, T.W., Schreurs, P.J.G. \& Schaufeli, W.B. (1999). Construct validity of the Maslach Burnout Inventory - General Survey: A two-sample examination of its factor structure and correlates. Work and Stress, 13, 223-237.

Tucker, L.R. \& Lewis, C. (1973). A reliability coefficient for maximum likelihood factor analysis. Psychometrika, 38, 1-10.

Wissing, M.P., de Waal, M. \& de Beer, I. (1992, July). Sense of coherence and stress symptomatology. Paper presented at $25^{\text {th }}$ International Congress of Psychology, Brussels, Belgium. 